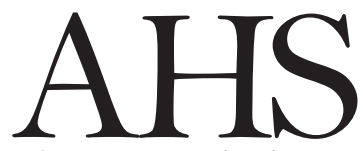

Advances in Horticultural Science

\title{
Artificial medium for in vitro pollen germination of some ornamental Linum species
}

\author{
V.A. Lyakh $1,2^{(*)}$, A.I. Soroka 2 \\ 1 Zaporozhye National University, Zhukovsky Str., 66, 69600 Zaporozhye, \\ Ukraine. \\ 2 Institute of Oilseed Crops, National Academy of Agricultural Sciences of \\ Ukraine, Institutskaya Str., 1, 70417 Zaporozhye, Ukraine.
}

Key words: Artificial medium, in vitro germination, Linum, pollen, polyethylene glycol, sucrose, wild species.

OPEN ACCESS

\footnotetext{
${ }^{(*)}$ Corresponding author:

lyakh@iname.com
}

Citation:

LYAKH V.A., SOROKA A.I., 2021 - Artificial medium for in vitro pollen germination of some ornamental linum species. - Adv. Hort. Sci., 35(3): 329-332.

Copyright:

(C) 2021 Lyakh V.A., Soroka A.I. This is an open access, peer reviewed article published by Firenze University Press

(http://www.fupress.net/index.php/ahs/) and distributed under the terms of the Creative Commons Attribution License, which permits unrestricted use, distribution, and reproduction in any medium, provided the original author and source are credited.

Data Availability Statement:

All relevant data are within the paper and its Supporting Information files.

Competing Interests:

The authors declare no competing interests.

Received for publication 5 May 2021 Accepted for publication 21 August 2021
Abstract: For the first time components of the nutrient medium were identified for the successful germination of pollen in such ornamental species of the Linum genus as $L$. grandiflorum, $L$. hirsutum, $L$. pubescens and $L$. thracicum. It was shown that the media with PEG-2000 in concentrations of $20-30 \%$ in combination with boric acid and calcium chloride in the concentrations of 200 $\mathrm{mg} / \mathrm{l}$ ensure germination of Linum pollen up to $40-50 \%$. The addition of sucrose and PEG with higher molecular weight adversely affects the germination of pollen. This will allow anyone to evaluate the quality of flax pollen quickly and efficiently and more successfully implement many genetic and breeding

\section{Introduction}

The Linum genus has between 100 and 230 species with the main representative of Linum usitatissimum L., which is one of the oldest cultivated plants, whose products have long been used for a variety of human needs. Not less diverse is the use of wild flaxes (Jhala et al., 2008; Lyakh and Soroka, 2008). Moreover, some annual and perennial wild relatives of the Linum genus, such as L. grandiflorum, L. pubescens, L. hirsutum, possessing fairly large flowers of various colors, are highly ornamental plants and are successfully applied in landscaping, flower bed arrangement, and gardening (Lyakh, 2013).

A number of wild Linum species is a producer of valuable substances for the pharmaceutical industry (Mohammed et al., 2009). Ushijima et al. (2012) reported that many wild flax species exhibit distinct floral polymorphism, which allows them to be used for elucidation the mechanisms of such a phenomenon as heterostyly. Wild flax relatives are also actively involved in phylogenetic analysis of the Linum genus (Muravenko et al., 2009; Sveinsson et al., 2014). programs. 
A broad use of wild flax species and active breeding work with them provides for knowledge of the quality of pollen, produced by the plant. The ability of pollen to grow and germinate on an artificial medium allows estimating its quality fast and effectively (Jayaprakash, 2018).

In flax, separate attempts were made to germinate pollen in vitro by Pandey and Kumar (2013). However, for the pollen of both cultivated flax and its wild relatives, the medium, which ensures the emergence of properly-shaped pollen tubes during pollen germination, has not yet been developed. In this respect the purpose of this work was to develop a nutrient medium suitable for the germination of pollen from a number of ornamental flax species.

\section{Materials and Methods}

Wild species L. grandiflorum Desf., L. hirsutum L., L. pubescens Banks and Solander and L. thracicum Degen were used in our studies as pollen sources. Experiments were carried out during 2017-2018.

The medium containing boric acid and calcium chloride in the concentrations of $200 \mathrm{mg} / \mathrm{l}$ was used as a basic one. A medium, consisting of boric acid, calcium chloride and sucrose as osmotic agent is commonly used for pollen germination of different species. We, however, excluded sucrose as according to our preliminary experiments with Linum species it inhibited completely pollen germination. Polyethylene glycol (PEG) of various molecular weights was supplied to the basic media (boric acid and calcium chloride) as osmotic agent. In some cases we also used sucrose as an addition to PEG. The following additions to the basic medium have been made: (a) PEG 2000, 20\%; (b) PEG 2000, 30\%; (c) PEG 2000, 30\% + sucrose, 5\%; (d) PEG 2000, 30\% + sucrose, $15 \%$; (f) PEG 6000, 30\% + sucrose, $5 \%$; (g) PEG 20000, $5 \%$ + sucrose, $15 \%$.

Pollen was collected from 20-40 flowers and germinated for 3-4 hours in a drop of an artificial medium placed on a slide at the temperature of $25 \pm 1{ }^{\circ} \mathrm{C}$ in the dark. The pollen was then viewed under a light Leica microscope (Germany) with a $20 X$ objective. Pollen grains were counted as germinated if the pollen tube length was more than a pollen grain diameter. In each 3-5 replication of each treatment several fields of view were analyzed to count from 300 to 400 pollen grains. Pollen grains near the margin of the medium were not recorded. After that a mean value of pollen germination percentage and a standard error of the mean were calculated (Lyakh and Soroka, 2008).

The results of the experiments were analyzed statistically applying a t-test, according to Wasserman (2005).

\section{Results and Discussion}

Figure $1 \mathrm{~A}$ shows that a medium containing PEG2000 as an osmotic in the concentration of $20 \%$ ensured a sufficiently good germination of the pollen for the species under study. The percentage of germinated pollen grains ranged from $22.9 \pm 2.44$ in $L$. thracicum to $51.0 \pm 2.84$ in L. grandiflorum. The elevation in concentration of PEG-2000 from $20 \%$ to $30 \%$ did not reduce this indicator in all species, except $L$. hirsutum, where an increment in the pollen germination was observed. Addition sucrose to the

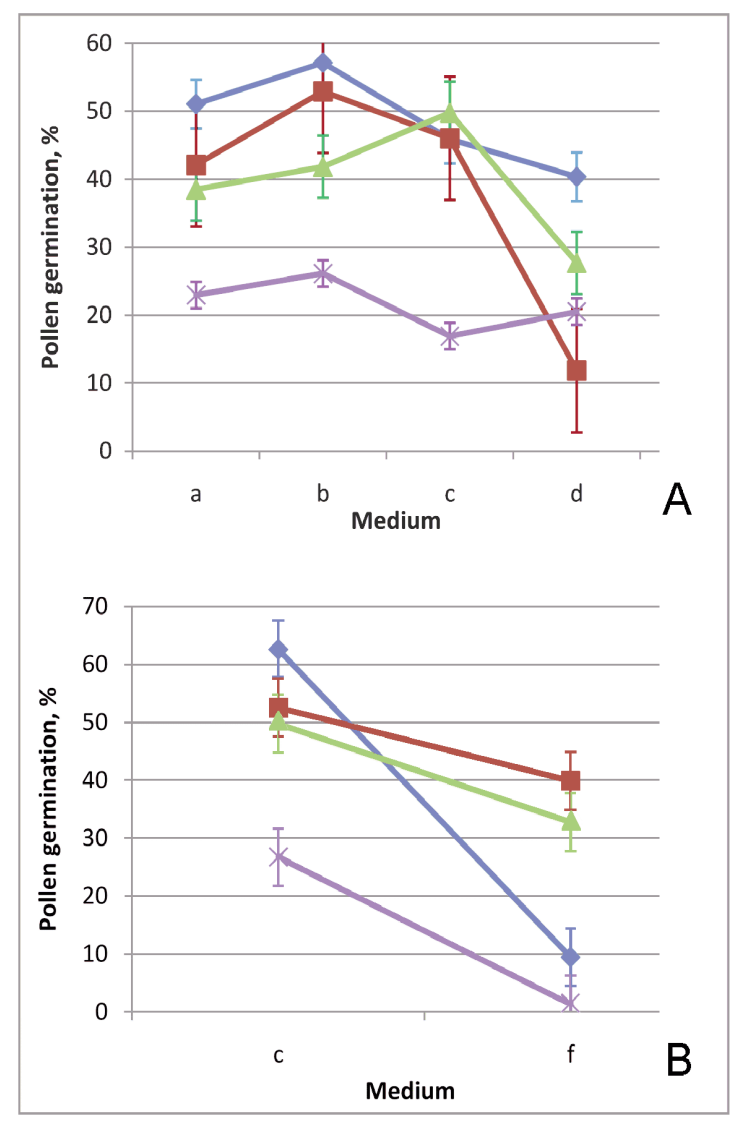

Fig. 1 - Influence of PEG-2000 concentration and sucrose addition (A) and PEG molecular weight (B) on pollen germination of some ornamental Linum species: -- - L. grandiflorum, $--\mathbf{- -}$ L. hirsutum, $--\Delta--L$. pubescens, $--X--L$. thracicum. 
nutrient medium with PEG-2000 adversely affected pollen germination as a whole. Elevating the sucrose concentration up to $15 \%$ in a medium with PEG $30 \%$ reduced the number of germinated grains in all the species. Figure $1 \mathrm{~B}$ data grant an idea on the influence of PEG with different molecular weight on pollen germination. As revealed, the percentage of pollen germination was significantly larger in the case of an osmotic with a lower molecular weight. It is characteristic that the number of germinated pollen grains on a medium supplied with PEG-6000, compared to PEG-2000, for L. grandiflorum and $L$. thracicum decreased by a factor of 6.6 and 20.5, whereas for L. pubescens and L. hirsutum - the reduction amounted to 34.0 and $24.1 \%$ only.

Figure 2 demonstrates pollen germination pattern on a media with PEG of different molecular weight and sucrose, showing the proportion of pollen grains with normal and burst pollen tubes. It can be seen that the percentage of pollen grains with burst tubes both in L. grandiflorum and L. hirsutum on a medium containing a high molecular weight polyethylene glycol (PEG-20000) at the concentration of $5 \%$, against the background of $15 \%$ sucrose, was quite large. It is characteristic that for some species it even exceeded the number of pollen grains with normal tubes. When the medium included PEG-20000 at the concentration of $30 \%$, pollen of all the studied species failed to germinate.
As can be seen, in our experiment sucrose negatively affected the germination of pollen when it was added to the media with PEG. With sucrose concentration increasing, the number of germinated pollen grains decreased notably. At the same time there are successful examples in the literature of the joint use of sucrose and PEG. Thus, for sunflower a nutrient medium was developed suitable for pollen germination which simultaneously included $15 \%$ of sucrose and $30 \%$ of PEG (Keshava Murthy et al., 1994). Such medium was successfully used to evaluate pollen response of various sunflower genotypes to the action of low temperature while selecting pollen for cold resistance (Lyakh and Totsky, 2014).

Analyzing the pollen germination of ornamental flax species on the media with PEG of different molecular weights, it is clearly noticeable that with an increase in the PEG molecular weight the degree of reduction of the studied indicator was different for different species. It can be assumed that such a difference in pollen response is due to the different osmotic potential of the pollen grains considering the natural habitat and presence a number of xeromorphic traits in L. hirsutum and L. pubescens as apposed to L. grandiflorum and L. thracicum (Tutin et al., 1968).

Pandey and Kumar (2013) have investigated in
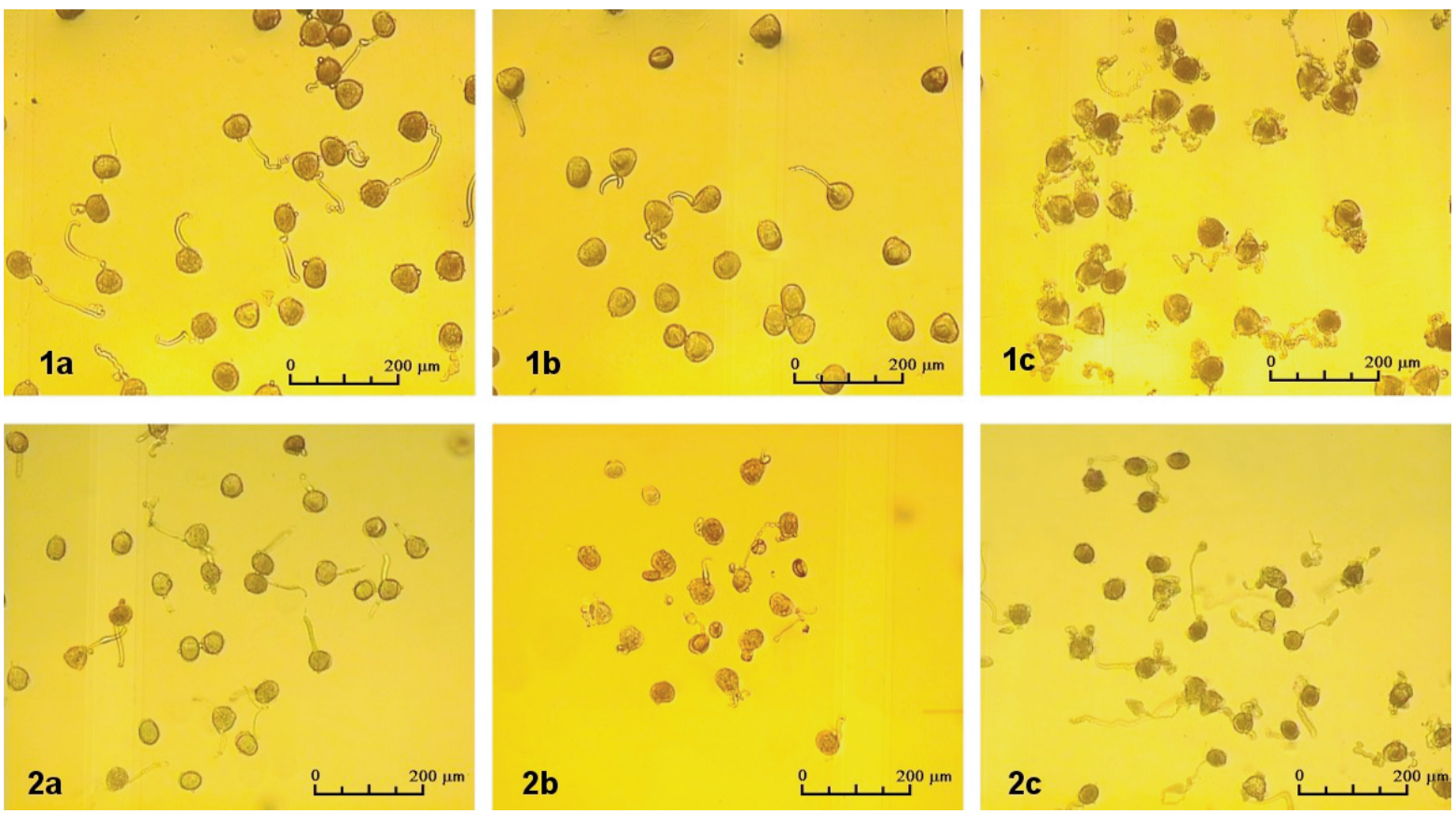

Fig. 2 - Pollen germination of L. grandiflorum (1) and L. hirsutum (2) on the media with PEG of different molecular weight and with sucrose: (a) PEG-2000, 30\% + sucrose, 5\% (b) PEG-6000, 30\% + sucrose, 5\%; (c) PEG-20000, 5\% + sucrose, $15 \%$. 
vitro pollen germination in L. usitatissimum on a medium containing as an osmotic only sucrose. However, despite the high ability of the pollen of this species to germinate under the given conditions, pollen grains emitted mostly pollen tubes with malformed morphology. In our experiment pollen of ornamental flax species germinated well and developed normal pollen tubes on the media containing, in addition to the basic components, PEG-2000 as an osmotic agent.

\section{Conclusions}

Wild species of the genus Linum are widely represented on the ornamental plant market. Moreover, their relatives can be used as a source material for fiber and oil flax breeding. For genetic and breeding programs pollen quality assessment is an important, and often necessary, procedure for their successful implementation. In vitro germination of pollen on artificial nutrient media is the simplest, but at the same time reliable way to determine the pollen viability. Our studies have shown that pollen of some wild species of the genus Linum germinates well on the media containing, in addition to boric acid and calcium chloride, an osmotic agent in the form of polyethylene glycol-2000. Replacing this osmotic with polyethylene glycol of a higher molecular weight or adding sucrose significantly impairs pollen germination rates. The patterns revealed allow to propose the composition of an artificial nutrient medium for germinating flax pollen, which will ensure its better germination than is known from the available scientific literature.

\section{References}

JAYAPRAKASH P., 2018 - Pollen germination in vitro, pp. 81-96 - In: MOKWALA P.W. (ed.) Pollination in plants. IntechOpen, London, UK.

JHALA A.J., HALL L.M., HALL J.C., 2008 - Potential hybridization of flax with weedy and wild relatives: an avenue for movement of engineered genes? - Crop Sci., 48: 825-840.
KESHAVA MURTHY M.N., NANJA REDDY Y.A., VIRUPAKSHAPPA K., 1994 - Development of suitable germination medium for trinucleate pollen grains: an illustration with sunflower. - J. Oilseeds Res., 11(20): 304-307.

LYAKH V., 2013 - Genetics of flower color in Linum grandiflorum Desf. - Indian J. Genetics Plant Breeding, 73: 335337.

LYAKH V.A., SOROKA A.I., 2008 - Botanical and cytogenetic peculiarities and biotechnological techniques for work with Linum L. genus species. - Zaporozhye National University, Zaporozhye, Ukraine.

LYAKH V.A., TOTSKY I.V., 2014 - Selective elimination of gametes during pollen storage at low temperature as a way to improve the genetic structure of sporophytic population for cold tolerance. - Helia, 37(61): 227-235.

MOHAMMED M.M.D., CHRISTENSEN L.P., IBRAHIM N.A., AWAD N.E., ZEID I.F., PEDERSEN E.B., 2009 - New acylated flavone and cyanogenic glycosides from Linum grandiflorum. - Natural Products Research, 23: 489497.

MURAVENKO O.V., YURKEVICH O.Y., BOLSHEVA N.L., SAMATADZE T.E., NOSOVA I.V., ZELENINA D.A., VOLKOV A.A., POPOV K.V., ZELENIN A.V., 2009 Comparison of genomes of eight species of sections Linum and Adenolinum from the genus Linum based on chromosome banding, molecular markers and RAPD analysis. - Genetica, 135(2): 245-255.

PANDEY S., KUMAR G., 2013 - Hazardous effect of gammarays on in vitro pollen germination and pollen tube growth in Linum usitatissimum L. - Chromosome Botany, 8: 31-34.

SVEINSSON S., MCDILL J., WONG G.K.S., LI J., LI X., DEYHOLOS M.K., CRONK Q.C.B., 2014 - Phylogenetic pinpointing of a paleopolyploidy event within the flax genus (Linum) using transcriptomics. - Annals of Botany, 113: 753-761.

TUTIN T.G., HEYWOOD V.H., BURGES N.A., MOORE D.M., VALENTINE D.H., WALTERS S.M., WEBB D.A., 1968 Flora Europea. Volume 2 Rosaceae to Umbelliferae. University Press, Cambridge, UK, pp. 489.

USHIJIMA K., NAKANO R., BANDO M., SHIGEZANE Y., IKEDA K., NAMBA Y., KUME S., KITABATA T., MORI H., KUBO Y., 2012 - Isolation of the floral morph-related genes in heterostylous flax (Linum grandiflorum): the genetic polymorphism and the transcriptional and post-transcriptional regulations of the S locus - The Plant Journal, 69: 317-331.

WASSERMAN L., 2005 - All of statistics: A concise course in statistical inference. - Springer Natura, New York, USA, pp. 442. 